\title{
Stability Study and Degradation Kinetics of Ceftazidime in Pharmaceutical Preparations
}

\author{
Andréia de Haro Moreno, Hérida Regina Nunes Salgado*
}

Department of Drugs and Medicines, School of Pharmaceutical Sciences, University of São Paulo State, Araraquara, 14801-902, Brazil

\begin{abstract}
Stability study of ceftazidime was realized in order to investigate kinetics of degradation of this drug both in powder for injection and reconstituted sample. Ceftazidime was submitted to conditions of accelerated thermal degradation and photodegradation. Analyses of the degraded samples were performed by microbiological assay and decomposition reactions could be described by zero-order and second-order kinetics. Results obtained confirm the reliability of the microbiological assay for determination of ceftazidime by the presence of its degradation products. The present study revealed thermal and photo lability of the drug, especially as reconstituted sample, and protection is recommended during storage and handling.
\end{abstract}

Keywords Ceftazidime, Stability Studies, Degradation Kinetics

\section{Introduction}

Stability is defined as the capacity of a drug substance or drug product to remain within established specifications to maintain its identity, strength, quality, and purity throughout the retest or expiration dating periods[1-3].

Due to their possible composition, pharmaceuticals are especially sensitive to environmental factors. Strict storage conditions are necessary for the maintenance of integrity and product activity. So, drug stability is considered to be a secure way to ensure delivery of therapeutic values to patients[4].

Stability testing of an active substance or finished product provides evidence on how the quality of a drug substance or drug product varies with time influenced by a variety of environmental factors such as temperature, humidity and light.

Knowledge from stability studies enables understanding of long-term effects of the drug environments[5].

Stability testing provides information about degradation mechanisms, potential degradation products, possible degradation pathways of drug as well as interaction between drug and excipients in pharmaceuticals. Results are applied in developing a suitable manufacturing process, selecting proper packaging, storage conditions, product's shelf life and expiration dates[6]. Brazilian stability studies guidelines were published in RE $\mathrm{n}^{\circ} 1$, in July 1st 2005, which determined specifications for stability analysis[7].

* Corresponding author:

salgadoh@fcfar.unesp.br (Hérida Regina Nunes Salgado)

Published online at http://journal.sapub.org/acc

Copyright (C) 2012 Scientific \& Academic Publishing. All Rights Reserved
Ceftazidime is a third-generation cephalosporin widely used for the treatment of serious infections caused by Gram-negative bacteria, including Pseudomonas aeruginosa, especially in cystic-fibrosis patients. It is usual to administer this drug by slow intravenous infusion over 24 hours. Infusion solutions are prepared in advance and stored in pharmacies[8-20].

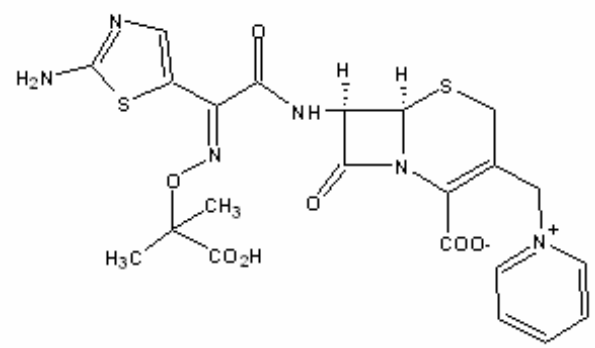

Figure 1. Chemical structure of ceftazidime $-\mathrm{C}_{22} \mathrm{H}_{22} \mathrm{~N}_{6} \mathrm{O}_{7} \mathrm{~S}_{2}$ (mw 546.58)

For many aqueous drug solutions, stress conditions such as $\mathrm{pH}$, temperature, light and oxidizing atmosphere can sometimes affect the maximum stability of the drug[21-22]. For this reason, the aim of this study was to evaluate the stability of ceftazidime in powder for injection and reconstituted sample against several stress conditions, such as temperature and both ultraviolet and visible radiation to determine the kinetics of degradation, describing concentration changes of ceftazidime as a function of time, as well as the kinetics run parameters. Recently, Moreno and Salgado published four methods for the analysis of ceftazidime in powder for injection: microbiological assay[23], high performance liquid chromatography[24] and spectrophotometry[25-26]. Analysis of the degraded 
samples were performed by microbiological assay[23], developed and validated in our laboratory in compliance with ICH guidelines[27].

\section{Material and Methods}

\subsection{Chemicals}

Ceftazidime reference substance (assigned purity 99.98\%) and ceftazidime powder for injection were kindly supplied by Ariston Química e Farmacêutica Ltda. (São Paulo, Brazil). Ceftazidime powder for injection $\left(\right.$ Ceftazidon $^{\mathrm{TM}}$ ) was claimed to contain $1000 \mathrm{mg}$ (as anhydrous base) of the drug and $118 \mathrm{mg}$ of anhydrous sodium carbonate as excipient (solubilizer).

Grove Randall number 1 agar and Grove Randall number 2 agar were obtained from Merck (Darmstadt, Germany). Tryptic Soy Broth was obtained from Difco (Rio de Janeiro, Brazil) and potassium phosphate was obtained from Synth (São Paulo, Brazil).

Distilled water was used to prepare all solutions for the microbiological assay.

\subsection{Instrumentation and analytical conditions}

\subsubsection{Thermal degradation}

Stress studies under thermal conditions were performed using a dry air oven Nova Etica ${ }^{\mathrm{TM}}$ (São Paulo, Brazil). Susceptibility of the drug in powder for injection to dry heat was studied by exposing it to $45^{\circ} \mathrm{C}$. For reconstituted sample, ceftazidime was dissolved in sterile distilled water and solutions were heated at $45^{\circ} \mathrm{C}$.

\subsubsection{Photodegradation}

Stress studies under day light conditions were performed using a D65/ID65 lamp (São Paulo, Brazil) and studies under ultraviolet conditions were performed using an UV Lamp SM 808 (Zheijang, China). Susceptibility of the drug in powder for injection and reconstituted sample (sterile aqueous solution) was evaluated by exposing it to visible and UV light distant $4 \mathrm{~cm}$ of the luminosity font.

\subsubsection{Microbiological assay}

Microbiological assay, applying the cylinder-plate method, was performed as described in an earlier publication[23].

\subsection{Decomposition studies}

Accelerated thermal degradation study was performed by heating commercial sample of ceftazidime $(1000 \mathrm{mg})$ at $45^{\circ} \mathrm{C}$ for $1,2,7,14,21$ and 28 days. At time intervals, amounts of degraded samples (three flasks for each time) were dissolved in sterile distilled water at concentration of $1000 \mu \mathrm{g} / \mathrm{mL}$. For reconstituted samples, commercial samples of ceftazidime $(1000 \mathrm{mg})$ were reconstituted to $10 \mathrm{~mL}$ of water (sterile distilled water) and stored at $45^{\circ} \mathrm{C}$ for 6,12 and 24 hours. Aliquots were withdrawn at suitable time intervals (three aliquots for each time) and diluted in sterile distilled water to give final concentration of $1000 \mu \mathrm{g} / \mathrm{mL}$.

Photodegradation studies were performed by exposing commercial samples of ceftazidime $(1000 \mathrm{mg})$ at ultraviolet radiation $(254 \mathrm{~nm})$ and visible radiation $(320 \mathrm{~nm})$ for 1, 2, 7, 14, 21 and 28 days. At time intervals, amounts of the degraded samples (three amounts for each time) were dissolved in sterile distilled water at concentration of 1000 $\mu \mathrm{g} / \mathrm{mL}$. For reconstituted sample, commercial samples of ceftazidime $(1000 \mathrm{mg})$ were reconstituted to $10 \mathrm{~mL}$ of sterile distilled water and exposed to ultraviolet $(254 \mathrm{~nm})$ and visible $(320 \mathrm{~nm})$ radiation for 6,12 and 24 hours. Aliquots were withdrawn at suitable time intervals (three aliquots for each time) and diluted in sterile distilled water to give final concentration of $1000 \mu \mathrm{g} / \mathrm{mL}$.

Dilutions were made in potassium phosphate buffer solution pH 6.0 to give final concentrations of 100.0, 200.0 and $400.0 \mu \mathrm{g} / \mathrm{mL}$, which were assayed against solutions of the reference substance at the same concentrations (linearity range)[23].

\subsection{Kinetic calculations}

Degradation rate kinetics was determined by plotting concentration of the remaining drug versus time (zero-order process) and concentration ${ }^{-1}$ of remaining drug versus time (second-order process). Kinetic parameters such as apparent order degradation rate constant $(k)$, half-life $\left(t_{1 / 2}\right)$ and $t_{90}$ (time where $90 \%$ of original concentration of the drug is left unchanged) were obtained from slopes of straight lines at each condition. Each experiment was done in triplicate, and average values were taken for the analysis.

\section{Results and Discussion}

Pharmaceutical product quality is of vital importance for patient's safety. The presence of impurities may influence the efficacy and safety of pharmaceuticals. Impurities and potential degradation products can cause changing of chemical, pharmacological and toxicological properties of drugs having significant impact on product quality and safety[28]. Stability study of pharmaceutical preparations became necessary to assure the purity, safety, potency and

Stress studies are said to be useful in determining accidental exposures to conditions other than those proposed as deleterious to the product, for evaluating which specific test parameters may be the best indicators of product stability and in revealing patterns of degradation. Mention of use of stress conditions was also found in some reports in the literature on the establishment of stability-indicating assays. Total information was tabulated for different types of activities, such as hydrolysis in acid, alkaline and neutral conditions, oxidation and photolysis and thermal degradation[27].

Accelerated aging traditionally involves use of temperature increases to speed reactions. The process of estimating ambient stability involves the prediction of the 
reaction rate at single or different temperature, and the extrapolation to the desired temperature[4].

Temperature has a high degree of influence on all varieties of chemical reactions and it is usually accelerated by raising the temperature. This is understandable since with increased temperature, molecules tend to move faster with increased kinetic energy. Additionally, the rate of collision molecules increases greatly. Finally, greater available energy causes more molecules to have enough activation energy and the fraction of collisions with suitable energy increases. It is typically said that a $10^{\circ} \mathrm{C}$ increase in temperature produces a 2-5 fold increase in decomposition[29-30].

In current pharmaceutical testing programs, the formation rate of individual products, independent of whether they are primary or secondary decomposition products of the drug, is the determining factor in setting shelf-life expiration. While drugs commonly decompose to give multiple products, the shelf-life is rarely determined by the overall drug

decomposition rate, but rather by the rate of formation of individual products as determined by their toxicity limits[4,31].

Light can have effects on the active principle in a drug formulation, as well as on the final product or packaging. This may be observed as bleaching of colored compounds or a discoloration of colorless products. The most obvious result of drug photodecomposition is the loss of potency of the product. As a final consequence, this can lead to a drug preparation, which is therapeutically inactive. Besides, amounts of photodegraded products formed in the pharmaceutical preparation may lead to adverse effects[28].

Basic information about photoreactivity of compounds is needed to provide information about handling, packaging, labeling and use of the drug substance or drug product. Knowledge about the mechanism by which

photodegradation occurs is of importance in stabilizing the product. Drug molecules may be directly or indirectly affected by irradiation, depending on how the radiant energy is transferred to the substance. Energy is imparted to the active substance, which subsequently degrades[32].

Light-sensitive drugs can be affected either by sunlight (especially ultraviolet irradiation) or artificial light sources (e.g. fluorescent light) and contribute to the

photodegradation of the active substance, occurring changes in physicochemical properties of the product, e.g. discoloration or cloudy appearance, viscosity loss, change in dissolution rate or precipitation[28].

Many drug substances are white and hence the degradation depends mostly on the amount of ultraviolet radiation absorbed by the material. Colored substances absorb light in the visible region of the spectrum. For this reason, stability studies should include exposures to both ultraviolet

and visible radiation to cover all possible degradation reactions [33].

In this study, thermal and photostability studies of ceftazidime were carried out through employment of stress conditions. Thermal degradation profile of ceftazidime was studied at $45^{\circ} \mathrm{C}$ for different time periods and the photodegradation was studied at both ultraviolet and visible radiation also for different time periods.

For reconstituted sample, drug was found to degrade extensively after reconstitution in aqueous solution. About $85 \%$ drug degradation was observed on exposures to heating at $45^{\circ} \mathrm{C}$ and to ultraviolet and visible radiation for $24 \mathrm{~h}$ (Table 1). A yellowish color developed there upon exposures of ceftazidime in reconstituted sample to heat and ultraviolet radiation.

Table 1. Experimental values obtained for the determination of ceftazidime (reconstituted sample) after exposition to temperature, and both ultraviolet and visible radiation

\begin{tabular}{cccc}
\hline Time & Temperature $\left(45^{\circ} \mathrm{C}\right)$ & UV radiation $(254 \mathrm{~nm})$ & VIS radiation $(320 \mathrm{~nm})$ \\
\cline { 2 - 4 } (h) & Found, $\%=$ S.E.M. & Found, $\%=$ S.E.M. & Found, $\%=$ S.E.M. \\
\hline 0 & $97.37=0.46$ & $97.51=0.54$ & $97.32=0.48$ \\
6 & $80.34=0.62$ & $88.37=0.41$ & $87.00=0.42$ \\
12 & $64.20=0.49$ & $70.44=0.51$ & $70.11=0.20$ \\
24 & $15.93=0.17$ & $14.76=0.16$ & $13.91=0.12$ \\
\hline
\end{tabular}

SEML = Sactard Errx of tha Mese

Each wile it the man of these desminationes

On exposures of ceftazidime to drug heat and ultraviolet and visible radiation in solid state (powder for injection), this drug was found to be stable. In this work, experiments were carried out using commercial samples, in sealed glass vials, protected from humidity. At $45^{\circ} \mathrm{C}$ with visible radiation, about only $8 \%$ of drug degraded after exposition for 28 days; at ultraviolet radiation exposure, the loss of drug was about only $5 \%$ (Table 2 ).

Table 2. Experimental values obtained for the determination of ceftazidime (powder for injection) after exposition to temperature, and both ultraviolet and visible radiation

\begin{tabular}{cccc}
\hline \multirow{2}{*}{$\begin{array}{c}\text { Time } \\
\text { (days) }\end{array}$} & Temperature $\left(45^{\circ} \mathrm{C}\right)$ & UV radiation $(\mathbf{2 5 4} \mathrm{nm})$ & VIS radiation $(320 \mathrm{~nm})$ \\
\cline { 2 - 4 } & Found, \% 0 S.E.M. & Found, $\%=$ S.E.M. & Found, $\%=$ S.E.M. \\
\hline 0 & $97.85=0.18$ & $97.50=0.41$ & $97.65=0.41$ \\
1 & $97.43=0.42$ & $97.29=0.71$ & $97.11=0.44$ \\
2 & $96.50=0.54$ & $97.07=0.76$ & $96.90=0.20$ \\
7 & $95.53=0.55$ & $96.76=0.68$ & $95.24=0.55$ \\
14 & $94.41=0.71$ & $96.28=0.64$ & $94.53=0.49$ \\
21 & $93.05=0.30$ & $95.70=0.83$ & $92.97 \pm 0.33$ \\
28 & $91.73=0.62$ & $94.90=0.70$ & $91.86 \pm 0.60$ \\
\hline
\end{tabular}

SEM = Sactart Erra of the Mise

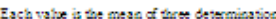

Plots of concentration of the drug remaining versus time obtained in the course of kinetic studies are shown in Fig. 2. At selected expositions, degradation processes of ceftazidime can be described by apparent zero-order and second-order kinetics for reconstituted sample and powder 
for injection, respectively. For reconstituted sample, strict straight-line behaviors were obtained for all expositions. Similar kinetic data were obtained for ceftazidime powder for injection. Correlation coefficients (r) observed for storage at $45^{\circ} \mathrm{C}$ and ultraviolet and visible radiations were $0.98,0.9934$ and 0.9843 , respectively. The kinetic models for zero-order and second-order degradation processes were confirmed. From slopes of straight lines it was possible to calculate the apparent first-order degradation rate constant, $k$, $t_{1 / 2}$ and $t_{90}$ at each exposure (Table 3 ).

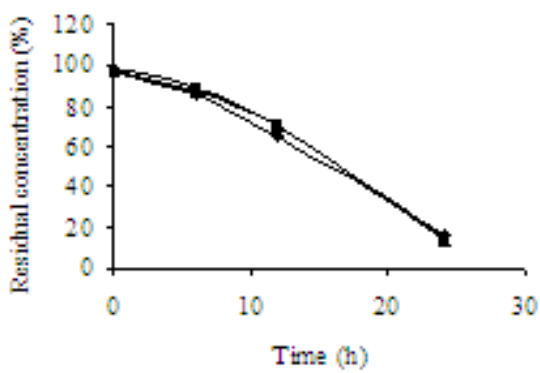

A

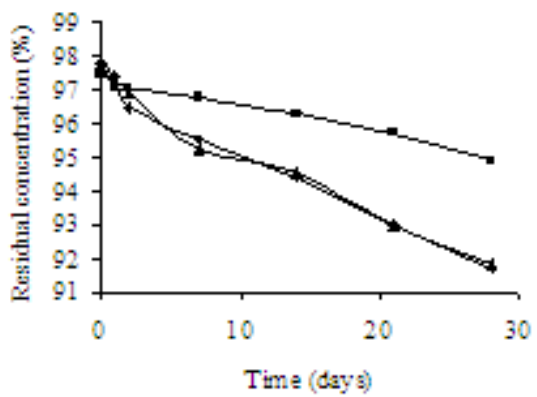

B

Figure 2. Comparative degradation profile of ceftazidime in reconstituted sample (A) and powder for injection (B) at $45^{\circ} \mathrm{C} \mathrm{( \bullet ),} 254 \mathrm{~nm}(\mathbf{-})$ and $320 \mathrm{~nm}$ (A)

Table 3. Degradation rate constant $(k)$, half-life $(t / / 2)$ and $t 90$ for ceftazidime in reconstituted sample and powder for injection, submitted to thermal and photodegradation, determined by microbiological assay

\begin{tabular}{ccccccc}
\hline & \multicolumn{3}{c}{ Reconstituted sample } & \multicolumn{3}{c}{ Powder for injection } \\
\cline { 2 - 7 } Exposition & $k\left(\mathrm{~h}^{-1}\right)$ & $t_{5 / 5}(\mathrm{~h})$ & $t_{90}(\mathrm{~h})$ & $k$ (days $\left.^{1}\right)$ & $t_{5 \text { (days) }}$ (dag & $t_{90}$ (days) \\
\hline $45^{\circ}$ & 3.247 & 15.07 & 3.01 & $3.85 \times 10^{-5}$ & 244 & 29 \\
$254 \mathrm{~nm}$ & 3.129 & 15.58 & 3.12 & $3.85 \times 10^{-5}$ & 265 & 34 \\
$320 \mathrm{~nm}$ & 3.162 & 15.44 & 3.09 & $3.85 \times 10^{-5}$ & 239 & 26 \\
\hline
\end{tabular}

The content of remaining ceftazidime was simultaneously determined by microbiological assay; this biodiffusion assay used was developed and validated by us[23]. Statistical analysis demonstrated the applicability of the method: there were no deviation from parallelism and linearity with the results obtained $(p<0.05)$.

Segregation and quantification of antibiotic components by chemical methods such as high-performance liquid chromatography, although precise, may not provide a true indication of biological activity, and attempts to correlate antibiotic bioassay results with those from chemical methods have usually been proved disappointing. So, results demonstrated that bioassays continue to play an essential role in manufacture and quality control of antibiotic medicines.

Stability study of drugs has as main goal to exposure the nature, kinetic course and degradation, as well as determini ng for how much time the product can conserve its original constitution[34-35]. Quality control in pharmaceutical industries is very important to guarantee effectiveness and confirm the quality of medicines commercialized for the population.

\section{Conclusions}

In this study, results showed reliability of microbiological assay for thermal and photodegradation kinetic study of ceftazidime. Degradation of this antibiotic during stress processing is found to follow first-order reaction kinetics. Extensive decomposition was observed for ceftazidime in aqueous solution when compared with solid state (powder for injection). Consequently, an appropriate protection is recommended during storage and handling of this antibiotic after reconstitution. This procedure can avoid the degradation of the drug and consequent loss of effectiveness and security of the product. These studies are important to establish storage type and adequate places for pharmaceutical preparations to prevent degradation after exposures, and guarantee the drug integrity, quality and security for users.

\section{ACKNOWLEDGEMENTS}

Authors thank Ariston Química e Farmacêutica Ltda. (São Paulo, Brasil) for providing ceftazidime reference substance and ceftazidime powder for injection. This work was supported by PACD-FCFAr-UNESP-Brazil, FUNDUNESP Brazil, FAPESP-Brazil and CNPq-Brazil.

\section{REFERENCES}

[1] N.E.S. Nudelman, Estabilidad de Medicamentos, Buenos Aires, Argentina: El Ateneo, 1975.

[2] Kalinkova, G.N., 1999, Studies of benefical interactions between active medicaments and excipients in pharmaceutical formulations, Int. J. Pharm., 187, 1-15.

[3] Ivanovic, I., Zivanovic, L., Zecevic, M., 2006, A stability indicating assay method for cefuroxime axetil and its application to analysis of tablets exposed to accelerated stability test conditions, J. Chromatogr. B, 1119, 209-215.

[4] Waterman, K.C., and Adami, R.C., 2005, Accelerated aging: prediction of chemical stability of pharmaceuticals, Int. J. Pharm., 293, 101-125. 
[5] E.B. Vadas, Estabilidade de Produtos Farmacêuticos, $20^{\text {th }}$ ed., Rio de Janeiro, Brazil: Guanabara Koogan, 2004.

[6] J.E. Thompson, A Prática Farmacêutica na Manipulação de Medicamentos, Porto Alegre, Brazil: Artmed, 2006.

[7] Resolução n.1, de 29 de julho de 2005. Diário Oficial (da República Federativa do Brasil), Brasília, 01 de agosto de 2005, Seção 1 .

[8] Myers, C.M., and Blumer, J.L., 1983, Determination of ceftazidime in biological fluids by using high-pressure liquid chromatography, Antimicrob. Agents Chemother., 24, 343-346.

[9] Rodenas, V., Garcia, M.S., Sanchez-Pedreno, C., Albero, M.I., 1997, Spectrophotometric methods for the determination of cephradine or ceftazidime in human urine using batch and flow-injection procedures, J. Pharm. Biomed. Anal., 15, 1687-1693.

[10] Arsène, M., Favetta, P., Favier, B., Bureau, J., 2002, Comparison of ceftazidime degradation in glass bottles and plastic bags under various conditions, J. Clin. Pharm.Therap., 27, 205-209.

[11] Adamis, G., Papaioannou, M.G., Giamarellos-Bourboulis, E.J., Gargalianos, P., Kosmidis, J., Giamarellou, H., 2004, Pharmacokinetic interactions of ceftazidime, imipenem and aztreonam with amikacin in healthy volunteers, Int. J. Antimicrob. Agents, 23, 144-149.

[12] A. R. Genaro, Remington: A Ciência e a Prática da Farmácia, $20^{\text {th }}$ ed., Rio de Janeiro, Brazil: Guanabara Koogan, 2004.

[13] J.G. Hardman and L.E. Limbird, The Pharmacological Basis of Therapeutics, New York: McGraw-Hill Book Co., 2006.

[14] Martindale, Guía Completa de Consulta Farmacoterapéutica, Barcelona, Spanish: Pharma Editores, 2006.

[15] Baskaran, N.D., Gan, G.G., Adeeba, K., Sam, I.C., 2007, Bacteremia in patients with febrile neutropenia after chemotherapy at a university medical center in Malaysia, Int. J. Infect. Dis., 23, 115-121.

[16] Cavallo, J.D., Hocquet, D., Plesiat, P., Fabre, R., Roussel-Delvallez, M., 2007, Susceptibility of Pseudomonas aeruginosa to antimicrobials: a 2004 French multicentre hospital study, J. Antimicrob. Agents Chemother., 59, 1021-1024.

[17] Claridge, J.A., Edwards, N.M., Swanson, J., Fabian, T.C., Weinberg, J.A., Wood, C., Croce, M.A., 2007, Aerosolized ceftazidime prophylaxis against ventilator-associated pneumonia in high-risk trauma patients: results of a double-blind randomized study, Surg. Infect. (Larchmt), 8, 83-90.

[18] Eagye, K.J., Kuti, J.L., Nicolau, D.P., 2007, Evaluating empiric treatment options for secondary peritonitis using pharmacodynamic profiling, Surg. Infect. (Larchmt), 8, 215-226.

[19] Martin, M.G., 2007, Encephalopathy with myoclonic jerks resulting from ceftazidime therapy: an under-recognized potential side-effect when treating febrile neutropenia, Leuk. Lymphoma, 48, 413-414.

[20] Raja, N.S., 2007, Melioidotic septic arthritis: a case report and literature review, J. Microbiol. Immunol. Infect., 40, 178-82.

[21] Stark, G., Fawcett, J.P., Tucker, I.G., Weatherall, I.L., 1996, Instrumental evaluation of color of solid dosage forms during stability testing, Int. J. Pharm., 143, 93-100.

[22] Lalitha, N., Sanjay, P.N., Vyshak, M.G., Kadri, U., 2010, Stability-indicating reverse phase HPLC method for the determination of cefazolin, Trop. J. Res., 9, 45-50.

[23] Moreno, A.H., and Salgado, H.R.N., 2007, Microbiological assay for ceftazidime injection, J. AOAC. Int., 90, 1379-1382.

[24] Moreno, A.H., and Salgado, H.R.N., 2008, Development of a new high-performance liquid chromatographic method for the determination of ceftazidime, J. AOAC Int., 91, 739-743.

[25] Moreno, A.H., and Salgado, H.R.N., 2008, Spectrophotometric determination of ceftazidime in pharmaceutical preparations using neocuproin as a complexing agent, Anal. Lett., 41, 2143-2152.

[26] Moreno, A.H., and Salgado, H.R.N., 2009, Rapid and selective UV spectrophotometric method for the analysis of ceftazidime, J. AOAC Int., 92, 820-824.

[27] ICH. Steering Committee, Technical requirements for registration of pharmaceuticals for human use, validation of analytical procedures: methodology. In: International Conference on Harmonization, Geneva, Switzerland, 1996.

[28] Tonnesen, H.H., 2001, Formulation and stability testing of photolabile drugs, Int. J. Pharm., 225, 1-14, 2001.

[29] A.O. Ferreira, Guia Prático da Farmácia Magistral, $2^{\text {nd }}$ ed., São Paulo, Brazil: Pharmabooks, 2002.

[30] E.S. Gil, R.M. Orlando, R. Matias, S.H. Serrano, Controle Físico-químico de Medicamentos, Campo Grande, Brazil: Uniderp, 2005

[31] A.T. Florence and D. Atwood, Princípios Físico-Químicos em Farmácia, São Paulo, Brazil: Edusp, 2003.

[32] H.C. Ansel, N.G. Popovich, L.V. Allen, Farmacotécnica: Formas Farmacêuticas e Sistemas de Liberação de Fármacos, São Paulo, Brazil: Editorial Premier, 2000.

[33] L. Lachman, H.A. Lieberman, J.L. Kanig, Teoria e Prática na Indústria Farmacêutica, Lisboa, Portugal: Fundação Calouste Gulbenkian, 2001.

[34] Marona, H.R.N., Zuanazzi, J.A.S., Schapoval, E.E.S., 1999, Determination of sparfloxacin and its degradation products by HPLC-PDA, J. Antimicrob. Chemother., 44, 301-302.

[35] Marona, H.R.N., and Schapoval, E.E.S., 2001, Analysis of sparfloxacin and its degradation products by bioassay, Acta Pharm. Turcica, 43, 7-9. 